\title{
A COMPARISON OF FUNCTIONAL OUTCOME BETWEEN TITANIUM INTERFERENCE SCREW AND ON LOOP-ENDOBUTTON FIXATION ON FEMUR IN ARTHROSCOPIC ANTERIOR CRUCIATE LIGAMENT RECONSTRUCTION
}

\author{
Md. Qamar Abdul Azeez ${ }^{1}$, Gudla Siva Prasad ${ }^{2}$
}

${ }^{1}$ Assistant Professor, Department of Orthopaedics, NRIIMS, Visakhapatnam, Andhra Pradesh, India.

${ }^{2}$ Associate Professor, Department of Orthopaedics, NRIIMS, Visakhapatnam, Andhra Pradesh, India.

\section{BACKGROUND}

ABSTRACT

Arthroscopic Anterior Cruciate Ligament [ACL] reconstruction is very commonly done procedure in recent times. ${ }^{\{1\}}$ Graft fixation methods vary from aperture fixation [Interference Screws] to suspensory fixation methods [Endobutton]. This is a Prospective non-randomised clinical study of arthroscopic ACL reconstruction comparing the functional results between fixation on femoral side with On Loop Endobutton and Fixation with Titanium Interference screw.

\section{MATERIALS AND METHODS}

Two groups of 10 patients who underwent autogenous hamstring ACL reconstruction with a minimum of 1 year follow up evaluation were included in the study. The aperture fixation group underwent Titanium interference screw fixation at both femoral and tibial tunnels. The suspensory fixation group underwent On Loop Endobutton fixation on the femoral side and Titanium interference screw on tibial side. Both group patients were examined prior to surgery and at 3 months, 6 months and 1 year. They were compared for functional outcome with Tegner Lysholm knee score.

\section{RESULTS}

There was significant improvement in functional outcome in both the groups between 0 and at 3 months, 3 months and 6 months, but from 6 months to 1 year. Group 2 has better statistically significant functional outcome.

\section{CONCLUSION}

In our prospective study of comparison of functional outcomes between aperture fixation and suspensory fixation on femur in arthroscopic ACL reconstruction which were evaluated by using Tegner Lysholm knee score over a period of 1 year, suspensory fixation was found to be better. However, further long-term studies involving large series of cases would throw more light on this information.

\section{KEY WORDS}

Titanium Interference Screw, Endobutton Fixation, Comparison, Arthroscopic Anterior Cruciate Ligament.

HOW TO CITE THIS ARTICLE: Azeez MQA, Prasad GS. A comparison of functional outcome between titanium interference screw and On loop-Endobutton fixation on femur in arthroscopic anterior cruciate ligament reconstruction. J. Evolution Med. Dent. Sci. 2018;7(51):5474-5478, DOI: 10.14260/jemds/2018/1211

\section{BACKGROUND}

Arthroscopic Anterior Cruciate Ligament [ACL] reconstruction is a very commonly done procedure in recent times.[1] The graft fixation methods vary from aperture fixation [Interference screws] to suspensory fixation methods [Endobutton] and trans condylar fixation [Rigid fix].[2] ACL graft fixation has been proposed to exert an essential influence on mechanical behaviour of the graft, though the biomechanics of the final construct will be determined by multiple factors.[2] Femoral fixation of the quadrupled hamstring graft is the key element to a durable ACL reconstruction. [2] There are many options available to achieve it. [2]

'Financial or Other Competing Interest': None.

Submission 07-06-2018, Peer Review 02-10-2018,

Acceptance 09-10-2018, Published 17-12-2018.

Corresponding Author:

Gudla Siva Prasad,

\#208, Department of Orthopaedics,

NRI Institute of Medical Sciences,

Besides ANITS Engineering College,

Sangivalasa, Visakhapatnam-530116,

Andhra Pradesh, India.

E-mail:dr_sivaji@yahoo.co.in

DOI: $10.14260 /$ jemds $/ 2018 / 1211$

\section{(c) (i) $(9)$}

The objective of this study was to compare the functional results between fixation on femoral side with On Loop Endobutton and Fixation with Titanium Interference screw in ACL reconstructions done by using hamstring auto graft.

\section{Aim of the Study}

Functional assessment of ACL reconstruction in two different femoral fixation methods by using interference screw and Endobutton.

\section{MATERIALS AND METHODS}

This was a prospective nonrandomised study on a series of 20 patients operated on for a Full thickness ACL tear, using hamstring tendon auto graft by two different technique of femoral fixation methods i. e Titanium interference screw and On- Loop Endobutton by the same surgical team, from January -1- 2017 to January- 1-2018 at NRI Medical College and hospital, Sangivalasa, Visakhapatnam.

\section{Inclusion Criteria}

1. Diagnosed to have complete ACL tear clinically and radiologically.

2. Age group 15 to 55 years.

3. Examined by single surgeon.

4. Radiological ACL deficient knee confirmed by MRI

5. Associated Menisci injuries. 


\section{Exclusion Criteria}

1. Observed chondral lesions that could modify the post op rehabilitation protocol.

2. Collaterals and/or PCL injuries.

3. Chronic ACL insufficiency with osteoarthritis.

4. Infection

5. Bilateral knee injuries.

6. Associated tibial plateau fractures. 7. Age above $55 \mathrm{yrs}$.

7. Previously operated knee.

All the patients were assessed clinically and confirmed on MRI. History of instability in the forms of sense of knee giving away, positive Lochmann's test and anterior drawer test were criteria based on which the patients were considered for surgery. All the patients were examined under anaesthesia. A positive Lachmann with soft end point and pivot shift test with glide or clunk were present in all patients. A data sheet containing mechanism of injuries, clinical and radiological examination findings with Tegner Lysholm score was completed. Initially all the cases underwent diagnostic arthroscopy through standard anterolateral portal and ACL tear was confirmed.

\section{Patients in Group 1}

First ten patients received Titanium interference screws both proximally and distally.

\section{Patients in Group 2}

Second ten received suspensory fixation [On-Loop Endobutton] proximally and Titanium interference screw distally. After getting informed consent from the patients, arthroscopic ACL reconstruction with hamstring tendon grafts which were fixed proximally by Titanium interference screw or Endobutton and distally by interference screws were undertaken.

\section{Surgical Technique}

The hamstring tendon was harvested through a $4 \mathrm{~cm}$ long incision $3 \mathrm{~cm}$ distal to joint line and $2 \mathrm{~cm}$ medial to tibial tuberosity. Both the semitendinosus and gracilis were harvested and prepared on the graft board with whip stitch by no 2 Ethibond and quadrupled. All were two portal technique single bundle ACL reconstruction with quadruple hamstring graft harvested from same side. In first ten patients fixation was achieved by both proximally and distally by Titanium interference screws. In second group of ten patients, fixation proximally by On-Loop Endobutton and distally by Titanium Interference screws. The femoral tunnel was made through trans portal. The tibial tunnel was done by an elbow aimer.

Post operatively knee immobilised in full extension with long knee brace, quadriceps, foot and knee exercise started on the second day, all patients underwent standardized rehabilitation protocol. Partial weight bearing was allowed for 10 to 14 days and full weight bearing by 2 to 3 weeks with range of motion, half squat. Stair climbing, cycling and jogging were allowed progressively and they were regularly followed up at 3, 6 and at 12th month. In addition to clinical, anterior drawer test and Lachman, radiological evaluations and functional outcomes were assessed by Tegner Lysholm score at, 3 months, 6months and 1year follow up. The Tegner Lysholm knee score calculated for 1Limp, 2Support, 3pain, 4instability, 5locking, 6swelling, 7stair climbing and 8 squatting. Each of these sections are further divided based on question arises and given score [e.g. 1 Pain a) none 5 b) slight or periodical $3 \mathrm{c}$ ) severe and constant 0$]$.

\section{RESULTS}

Of the 20 patients, all were men [95\%] except one female [5\%] in the age group of 16 to 53. Mean age in group 1 was 31.7 and in 2 nd group was 33. Right. and left knee were involved equally in group 1 . In group $2,70 \%$ were right knee only[3] 30\% were left knee. The mode of injury in majority was twisting injury during activities 10 [50\%] and RTA 8 [40\%]. Additional injuries in group -1 two had medial meniscus tear and two had lateral meniscus. In group 2 two had medial meniscus tear. At follow up Group 1 mean Tegner lysholm knee scores at preop, 3, 6 and 12 month follow up were 74.2, 73.7, 93.5 and 92.5 respectively. Group 2 the mean Tegner lysholm knee score were 74, 74, 94 and 98 respectively. Both the groups were comparable with respect to pre-operative variables. In each group, there was significant improvements in functional outcomes over successive follow-ups. The comparison of functional outcomes between two groups revealed that there was significant improvement in functional outcome in both the groups between 0 and 3 months, 3 months and 6 months, but from 6 months to 1 year Group 2 has better statistically significant functional outcome.

\begin{tabular}{|c|c|c|}
\hline Criteria & $\begin{array}{c}\text { Group 1- } \\
\text { Interference Screw }\end{array}$ & $\begin{array}{c}\text { Group 2 - On- } \\
\text { Loop Endobutton }\end{array}$ \\
\hline $\begin{array}{c}\text { Number of } \\
\text { patients [\%] }\end{array}$ & $10[50 \%]$ & $10[50 \%]$ \\
\hline $\begin{array}{c}\text { Mean age of } \\
\text { patients }\end{array}$ & 31.7 & 33 \\
\hline $\begin{array}{c}\text { Time from injury } \\
\text { to surgery }\end{array}$ & 1month -3 years & 1month -4 years \\
\hline \multicolumn{2}{|c|}{ Table 1. Basic Data of Study Patients } \\
\hline
\end{tabular}

\begin{tabular}{|c|c|c|c|c|c|}
\hline & N & Mean & $\begin{array}{c}\text { Std. } \\
\text { deviation }\end{array}$ & Min. & Max. \\
\hline TLSCORE_PRE OP & 10 & 74.20 & 2.936 & 69 & 77 \\
\hline TLSCORE_3M & 10 & 73.70 & 2.406 & 68 & 76 \\
\hline TLSCORE_6M & 10 & 93.50 & 3.028 & 90 & 100 \\
\hline TLSCORE_1Yr & 10 & 92.50 & 2.635 & 90 & 95 \\
\hline a. Group = 1 & & & & \\
\hline \multicolumn{7}{|c|}{ Table 2. Group = 1 Descriptive Statistics a } \\
\hline
\end{tabular}

\begin{tabular}{|c|c|}
\hline & Mean Rank \\
\hline TLSCORE_PRE OP & 1.65 \\
\hline TLSCORE_3M & 1.35 \\
\hline TLSCORE_6M & 3.50 \\
\hline TLSCORE_1Yr & 3.50 \\
\hline a. Group $=1$ & \\
\hline \multicolumn{2}{|c|}{ Table 3. Friedman Test Ranks ${ }^{\boldsymbol{a}}$} \\
\hline
\end{tabular}

\begin{tabular}{|c|c|}
\hline $\mathbf{N}$ & $\mathbf{1 0}$ \\
\hline Chi. square & 25.021 \\
\hline Df & 3 \\
\hline Asymp. sig & .000 \\
\hline a. Group=1 \\
\hline b. Freidman test \\
\hline \multicolumn{2}{|c|}{ Table 4. Test Statistics, $\boldsymbol{b}$} \\
\hline
\end{tabular}


Note: $\mathrm{p}$-value $=.000$ hence there is a statistical difference between the scores of three readings.

\begin{tabular}{|c|c|c|c|c|c|}
\hline & N & Mean & Std. Deviation & Min. & Max. \\
\hline TLSCORE_PRE OP & 10 & 74.20 & 2.974 & 69 & 77 \\
\hline TLSCORE_3M & 10 & 74.40 & 1.174 & 73 & 76 \\
\hline TLSCORE_6M & 10 & 94.00 & 2.789 & 90 & 100 \\
\hline TLSCORE_1Yr & 10 & 98.00 & 2.582 & 95 & 100 \\
\hline b. Group = 2 & \multicolumn{3}{|c|}{ Table 5. Group = 2 Descriptive Statistics $\boldsymbol{b}$} \\
\hline \multicolumn{7}{|l}{}
\end{tabular}

\begin{tabular}{|c|c|}
\hline & Mean Rank \\
\hline TLSCORE_PRE OP & 1.60 \\
\hline TLSCORE_3M & 1.40 \\
\hline TLSCORE_6M & 3.10 \\
\hline TLSCORE_1Yr & 3.90 \\
\hline b. Group $=2$ & \\
\hline \multicolumn{2}{|c|}{ Table 6. Friedman Test Ranks } \\
\hline
\end{tabular}

\begin{tabular}{|c|c|}
\hline $\mathbf{N}$ & $\mathbf{1 0}$ \\
\hline Chi. square & 26.040 \\
\hline Df & 3 \\
\hline Asymp. sig & .000 \\
\hline a. Group $=1$ & \\
\hline b. Freidman test & Table 7. Test Statistics $^{\boldsymbol{a}, \boldsymbol{b}}$ \\
\hline \multicolumn{2}{|c|}{ Table }
\end{tabular}

Note: $p$-value $=.000$ hence there is a statistical difference between the scores of three readings for group 2 also.

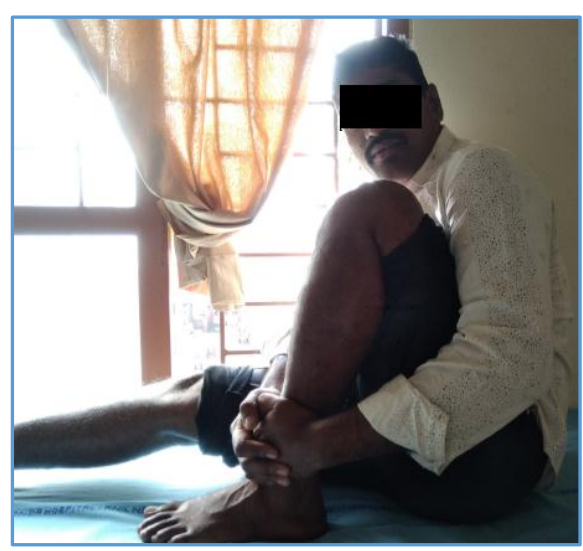

Figure 1. 1 Yr. Followup Fixation with Interference Screw Showing Good ROM

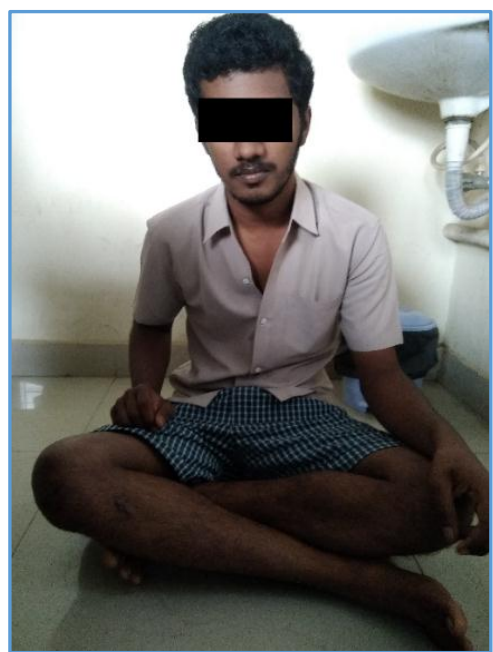

Figure 2. 1 Yr. Followup Case of on Loop Endobutton Fixation

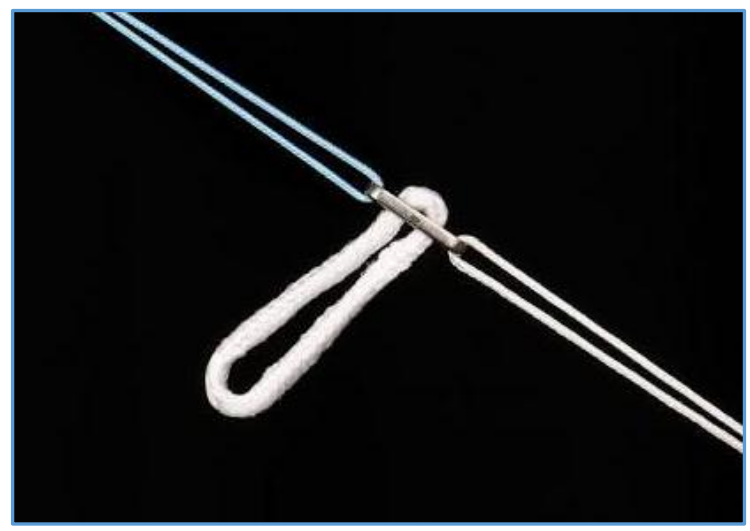

Figure 3

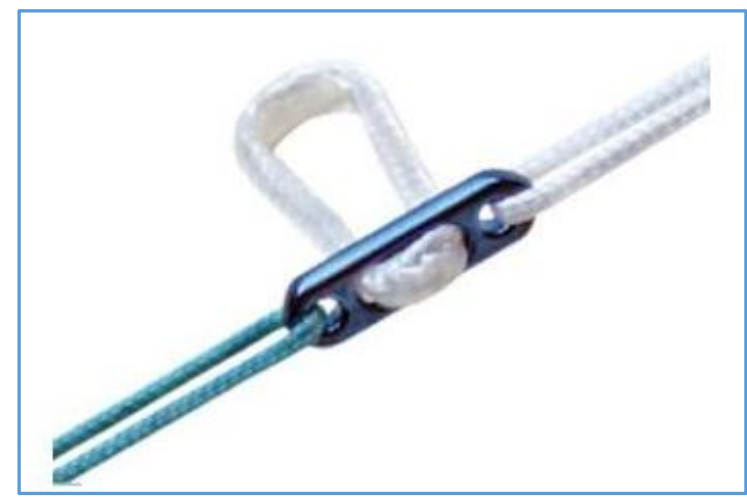

Figure 4

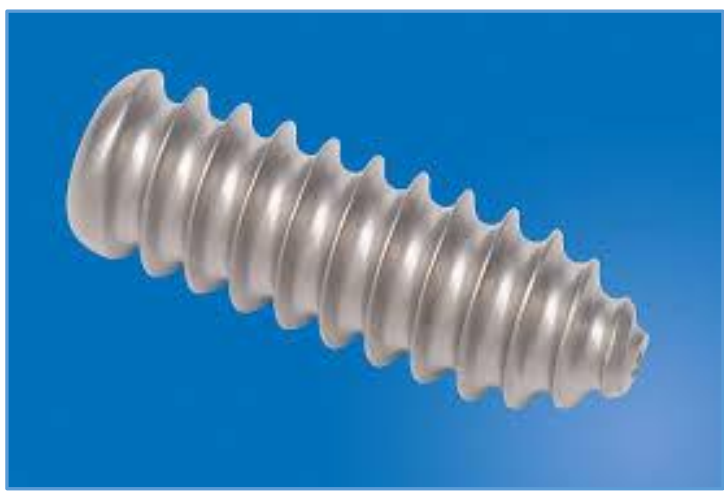

Figure 5

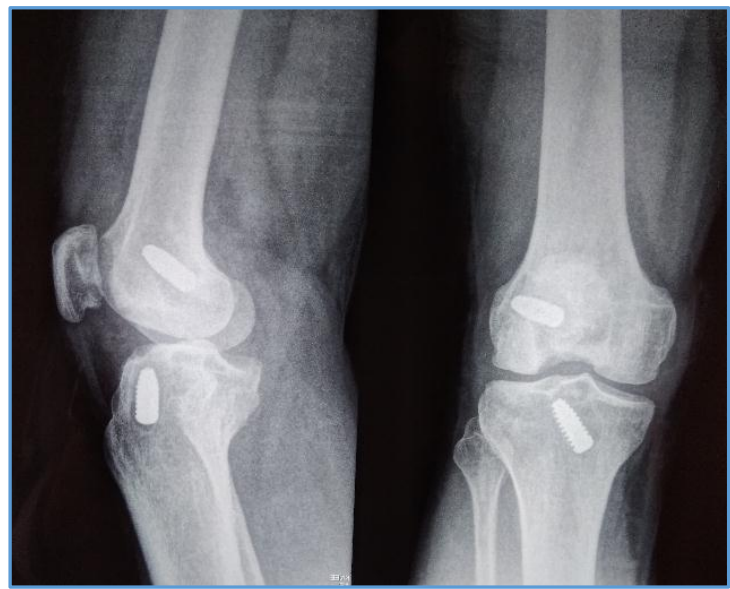

Figure 6. X Ray Showing Graft Fixation with Interference Screws 


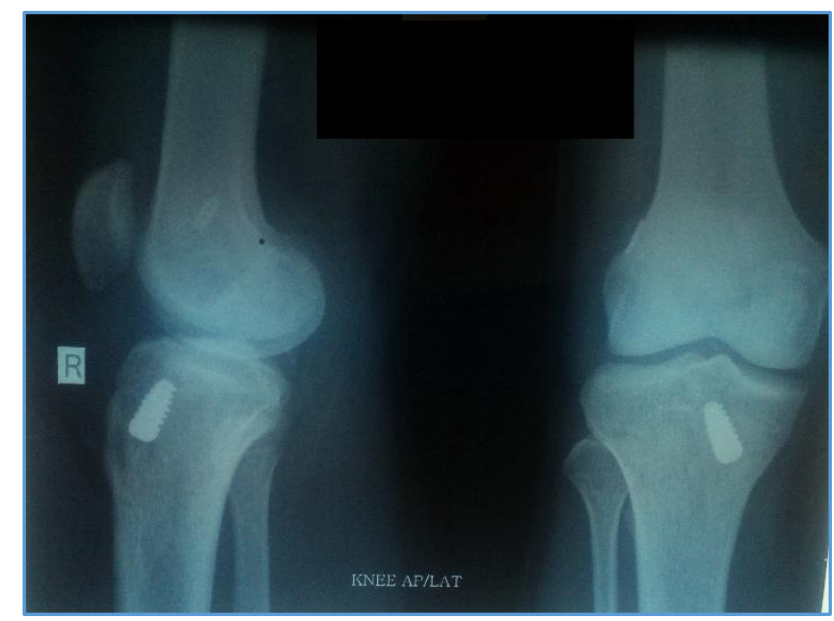

Figure 7. X Ray Showing Graft Fixation with on Loop Endobutton

\section{DISCUSSION}

ACL tear is commonly treated arthroscopically by using hamstring autograft or bone patellar tendon bone [BPTB] graft. ${ }^{[3,4]}$ The use of hamstring graft has become increasingly popular. This is because the ultimate tensile strength of the quadruple graft is as high as $4108 \mathrm{~N}$ with a stiffness of 807 N.[3] Donor site morbidities like patellar fracture, patellar tendon rupture, quadriceps weakness and anterior knee pain as seen in patellar BPTB graft are considerably lessened with hamstring graft. ${ }^{[5]}$ Noyes et al demonstrated that the stiffness of a semitendinosus graft is nearly equal to that of the ACL, while BPTB grafts are approximately 3.76 times stiffer than the ACL.[3] Thus a four strand hamstring graft appears to be stronger than comparable BPTB grafts and closer to linear stiffness of the anterior cruciate ligament. There are mainly two types of fixation devices used in ACLR in bone tunnels: A) Aperture fixation means the fixation of a graft at the opening of the bone tunnel like interference screws [Intrafix] etc, and B) suspensory fixation of the graft that is remote from the intra-articular space. Aperture graft fixation device includes a screw, post, and washer, etc, whereas suspensory fixation of graft is done using sutures suspended from a femoral fixation device like an Endobutton (Smith \& nephew) or Transfix (Arthrex). The main purpose of these devices is to provide a secure fixation so that the graft gets proper healing into the tunnel. This further helps in starting early range of motion exercise and weight-bearing and hence, the early return to sports without any loss of fixation. The choice of fixation of the graft varies from screws to cortical fixation like Endobutton and rigid fix.[5] Several techniques are in use, with success rates of between $65 \%$ and $90 \%$.[6] The use of interference screws for graft fixation is considered to provide higher fixation strength as compared with other devices such as staples or buttons.[7, 8]The choice of fixation devices for ACLR is mostly surgeon -dependent.[9] Hakimi, et al.[9] found that in the UK the hamstring femoral fixation was done with a suspension device in $79 \%$ and interference screw in $18 \%$. Of those using a suspension device, the Endobutton was most common (48\%), followed by Transfix (26\%) and Rigid Fix (19\%). Tibial fixation was most commonly achieved by interference screw (57\%) followed by intra fix (30\%). Kim, et al. concluded that the type of graft fixation device did not affect the clinical outcome and stability. ${ }^{[10]}$ The Endobutton is commonly used and is relatively in- expensive. The point of fixation lies some distance from the joint. There is a nylon material present between the graft and button. This technique is prone to drill tunnel enlargement, possibly so called bungee effect.[11,12] Also windshield wiper effect is also associated.[11,12] This suspensory fixation has been associated with high failure load and tunnel widening due to graftrelated micro motions in to the bony tunnel and anterior joint laxity.[13] The choice of interference screw material has seen a recent change in the use pattern, from metal screws to biodegradable screws. Ma, et al.[14] Found no difference between metal and biodegradable screw usage clinically. Noticeable tunnel widening was seen in both groups, especially on the femoral side. In our study we have used Interference screw and Endobutton. Both modes of fixation of ACL reconstruction are associated with improved function and satisfaction of patients as indicated by Lysholm score and anterior drawer test after surgery. However by considering the Tegner Lysholm score magnitudes of both the groups we feel the group 2 Endobutton fixation is better clinically as compared group 1 because the score is statistically same for pre-op and at 3 months and for 3 months and 6 months between the groups but for group 2 it is almost significant for 6 months to 1 year where as it is not for group 1 interference screw fixation.

The Limitations of the study are small number of patients (20) and short duration of one year. Besides we have applied the Tegner Lysholm score for evaluation of the patient's outcome and did not use other methods of scoring systems.

\section{CONCLUSION}

In our study, we prospectively compared the functional outcomes after doing ACL reconstruction by hamstring graft which were fixed by using Titanium Interference Screws and suspensory fixation with On-Loop Endobutton at femur and Interference Screw at tibia. Functional assessment was done on basis of Tegner Lysholm score. The Endobutton fixation yielded better outcome in terms of instant stability of the graft and functional outcome at the end of one year.

\section{Abbreviations \\ ACL- Anterior Cruciate Ligament \\ BPTB- Bone Patellar Tendon Bone \\ ACLR- Anterior Cruciate Ligament Reconstruction}

\section{REFERENCES}

[1] Hughes G, Watkins J. A risk factor model for anterior cruciate ligament injury. Sports Med 2006;36(5):41128.

[2] Frank CB, Jackson DW. The science of reconstruction of the anterior cruciate ligament. J Bone Joint Surg Am 1997;79(10):1556-76.

[3] Noyes FR, Butler DL, Grood ES, et al. Biomechanical analysis of human ligament grafts used in knee ligament grafts used in knee ligament repairs and reconstructions. J Bone Joint Surg Am 1984;66(3):34452. 
[4] Eriksson K, Anderberg P, Hamberg P, et al. A comparison of quadruple semitendinosus and patellar tendon graft in reconstruction of the anterior cruciate ligament. J Bone J Surg Br 2001;83(3):348-54.

[5] Kleipool A, van Loon T, Marti RK. Pain after use of the central third of the patellar tendon for cruciate ligament reconstruction. 33 patients followed 2-3 years. Acta Orthop Scan 1994;65(1):62-6.

[6] Emond CE, Woebler EB, Kurd SK, et al. A comparison of the results of anterior cruciate ligament reconstruction using bioabsorbable versus metal interference screws: a meta-analysis. J Bone and Joint Surg Am 2011;93(6):572-80.

[7] Kurosaka M, Yoshiya S, Andrish JT. A biomechanical comparison of different surgical techniques of graft fixation in anterior cruciate ligament reconstruction. Am J Sports Med 1987;15(3):225-9.

[8] Woo SL, Wu C, Dede O, et al. Biomechanics and anterior cruciate ligament reconstruction. J Orthop Surg Res 2006;1:2.

[9] Hakimi M, Anand S, Sahu A. ACL Reconstruction current UK practice. J Bone Joint Surg Br 2012;94B:42.
[10] Kim HS, Seon JK, Jo AR. Current trends in anterior cruciate ligament reconstruction. Knee Surg Relat Res 2013;25(4):165-73.

[11] Hoher J, Livesay GA, Ma CB, et al. Hamstring graft motion in the femoral bone tunnel when using titanium button/polyester tape fixation. Knee Surg Sports Traumatol Arthrosc 1999;7(4):215-9.

[12] Nebulung W, Becker R, Merkel M, et al. Bone tunnel enlargement after anterior cruciate ligament reconstruction with semitendinosus tendon using Endobutton fixation on the femoral side. Arthroscopy 1998;14(8):810-5.

[13] Ishibashi Y, Rudy TW, Livesay GA, et al. The effect of anterior cruciate ligament graft fixation site at the tibia on knee stability: evaluation using a robotic testing system. Arthroscopy 1997;13(2):177-82.

[14] Ma CB, Francis K, Towers J, et al. Hamstring anterior cruciate ligament reconstruction: a comparison of bioabsorbable interference screw and Endobuttonpost fixation. Arthroscopy 2004;20(2):122-8. 